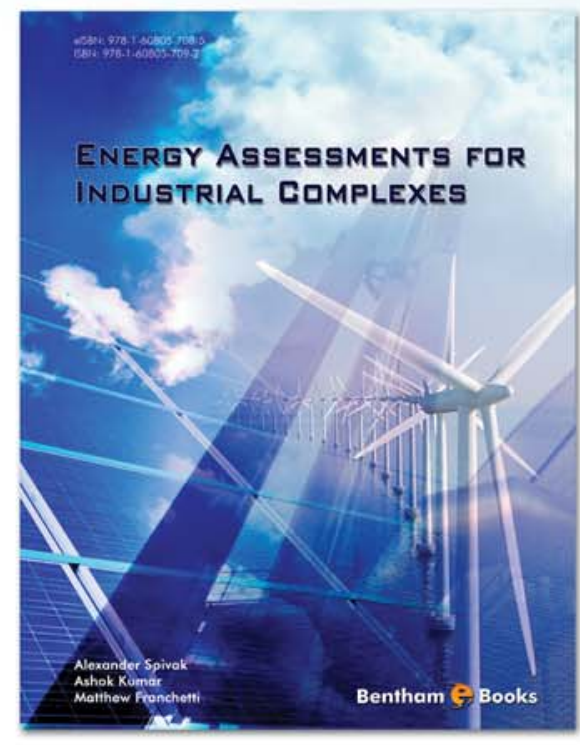

\title{
Authors:
}

Alexander Spivak Ashok Kumar

USA

\author{
Ashok Kumar \\ USA
}

\section{Matthew Franchetti}

USA

elSBN: 978-1-60805-708-5

\section{Energy Assessments for Industrial Complexes}

\section{WWW.Lenthamseience.com/ehooks/9781608057085}

\section{About the ebook}

This e-book discusses methods that businesses may employ to reduce energy costs related to managing industrial buildings through environmentally sustainable methods. There are several chapters covering various aspects of energy assessments and each chapter is linked to case histories that are given in the appendix. The chapters cover energy efficient methods for managing lighting, insulation, machines, air conditioning and much more. Information needed during the assessment process is also supplemented in tables. Readers who wish to gain a better understanding of[] the many ways to reduce energy consumption can benefit from this book.

For Sales and Advertising Inquiries: Contact: marketing@benthamscience.org 